\title{
Hypophysitis Secondary to Cytotoxic T-Lymphocyte-Associated Protein 4 Blockade
}

\section{Insights into Pathogenesis from an Autopsy Series}

\author{
Patrizio Caturegli, * Giulia Di Dalmazi, ${ }^{* \dagger}$ Martina Lombardi ${ }^{\ddagger}$ Federica Grosso, ${ }^{\S}$ H. Benjamin Larman, ${ }^{*}$ Tatianna Larman, * \\ Giacomo Taverna, "Mirco Cosottini," and Isabella Lupi**
}

\begin{abstract}
From the Division of Immunology, * Department of Pathology, The Johns Hopkins School of Medicine, Baltimore, Maryland; the Department of Medicine, G. D'Annunzio University of Chieti, Chieti, Italy; the Endocrinology Unit ${ }^{\ddagger}$ and the Oncology Center, ${ }^{\S}$ Saints Anthony and Biagio, and Cesare Arrigo Hospital, Alessandria, Italy; the Department of Radiology, ${ }^{\top}$ Mesothelioma Unit, Saint Spirit Hospital, Casale Monferrato, Italy; and the Department of Translational Research and New Technologies in Medicine and Surgeryll and Endocrinology, ** University of Pisa, Pisa, Italy
\end{abstract}

\author{
Accepted for publication \\ August 10, 2016. \\ Address correspondence to \\ Patrizio Caturegli, M.D., \\ M.P.H., Johns Hopkins Pathol- \\ ogy, Room 656, Ross Bldg, 720 \\ Rutland Ave, Baltimore, \\ MD 21205. E-mail: pcat@ \\ jhmi.edu.
}

\begin{abstract}
Hypophysitis that develops in cancer patients treated with monoclonal antibodies blocking cytotoxic T-lymphocyte-associated protein 4 (CTLA-4; an inhibitory molecule classically expressed on T cells) is now reported at an incidence of approximately $10 \%$. Its pathogenesis is unknown, in part because no pathologic examination of the pituitary gland has been reported to date. We analyzed at autopsy the pituitary glands of six cancer patients treated with CTLA-4 blockade, one with clinical and pathologic evidence of hypophysitis, one with mild lymphocytic infiltration in the pituitary gland but no clinical signs of hypophysitis, and four with normal pituitary structure and function. CTLA-4 antigen was expressed by pituitary endocrine cells in all patients but at different levels. The highest levels were found in the patient who had clinical and pathologic evidence of severe hypophysitis. This high pituitary CTLA-4 expression was associated with T-cell infiltration and IgG-dependent complement fixation and phagocytosis, immune reactions that induced an extensive destruction of the adenohypophyseal architecture. Pituitary CTLA-4 expression was confirmed in a validation group of 37 surgical pituitary adenomas and 11 normal pituitary glands. The study suggests that administration of CTLA-4 blocking antibodies to patients who express high levels of CTLA-4 antigen in the pituitary can cause an aggressive (necrotizing) form of hypophysitis through type IV (T-cell dependent) and type II (IgG dependent) immune mechanisms. (Am J Pathol 2016, 186: 3225-3235; http://dx.doi.org/ 10.1016/j.ajpath.2016.08.020)
\end{abstract}

Hypophysitis is a chronic inflammation of the pituitary gland of idiopathic (primary) or known (secondary) etiology. ${ }^{1}$ Primary hypophysitis is rare but significant because it enters in the differential diagnosis of other, more common, non-hormone-secreting pituitary masses, such as pituitary adenomas. It typically presents with signs and symptoms of sellar compression and/or various degrees of hypopituitarism. If unrecognized, it can also cause death because of irreversible adrenal insufficiency. Primary hypophysitis encompasses a spectrum of pathologic lesions, ${ }^{2,3}$ ranging from the most common lymphocytic and granulomatous variants to the more recently described xanthomatous, ${ }^{4}$ IgG4 plasmacytic, ${ }^{5}$ and necrotizing ${ }^{6}$ variants. A total of
1005 patients with primary hypophysitis have been described in publications from 1917 to June 2016 (Table 1), diagnosed by surgical pathology [631 (63\%)], clinical and imaging criteria [331 (33\%)], or autopsy [43 (4\%)].

Hypophysitis secondary to the administration of monoclonal antibodies directed against cytotoxic T-lymphocyteassociated protein 4 (CTLA-4), a molecule classically expressed on $\mathrm{T}$ cells, was first reported in $2003^{7}$ and first reviewed in 2009. ${ }^{8}$ This form of hypophysitis is now observed in approximately $10 \%^{9-11}$ of cancer patients

Supported by NIH grant RO1 CA-194042 (P.C.).

Disclosures: None declared. 
Table 1 Key Features of Primary Hypophysitis and Hypophysitis Secondary to CTLA-4 Blockade

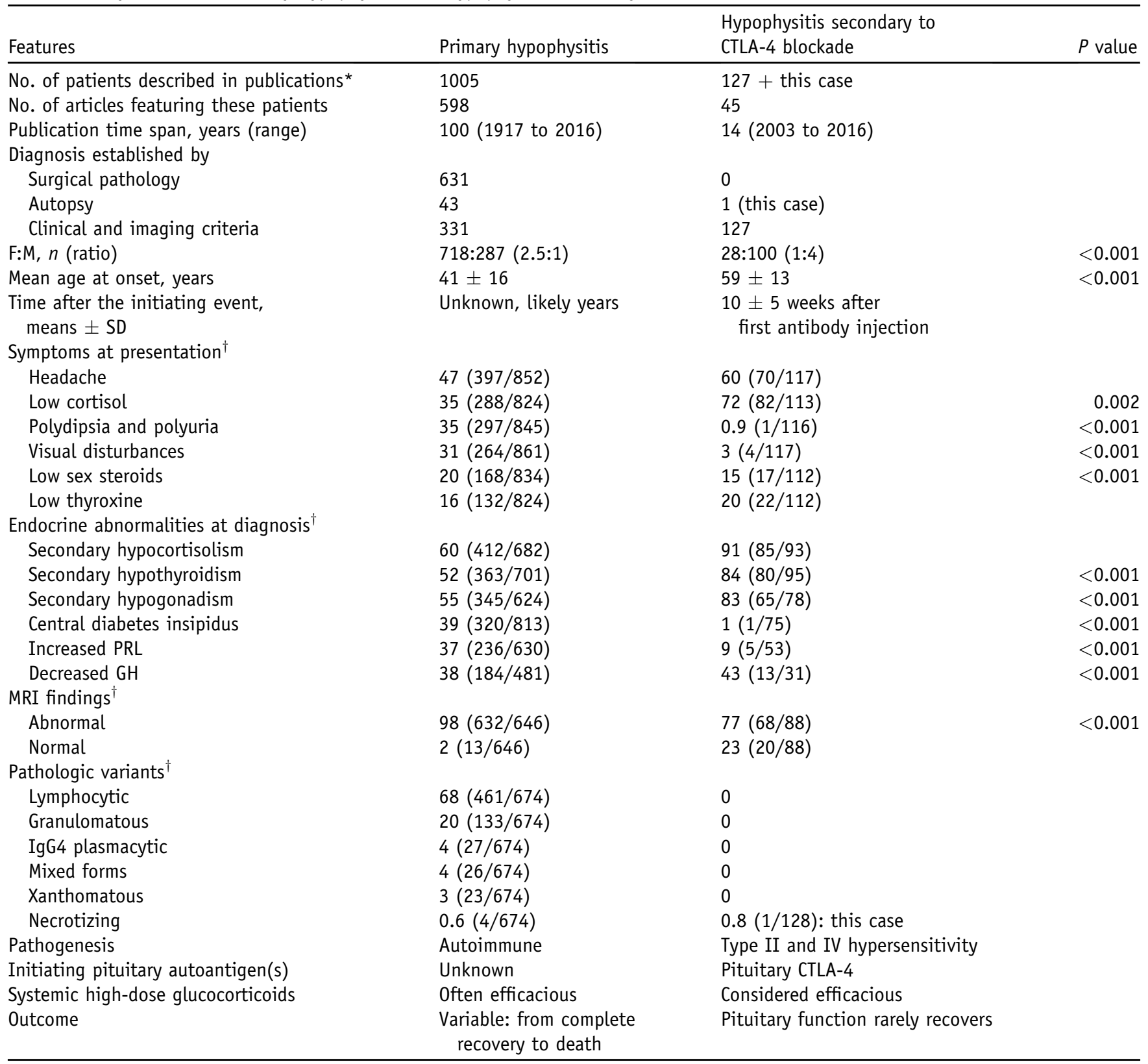

*Meeting abstracts are not included.

${ }^{\dagger}$ Data are given as \% (number/total).

F, female; M, male; CTLA-4, cytotoxic T-lymphocyte-associated protein 4; GH, growth hormone; MRI, magnetic resonance imaging; PRL, prolactin.

treated with ipilimumab (an IgG1 produced by BristolMyers Squibb, New York, NY). It occurs less frequently in patients receiving tremelimumab (an $\operatorname{IgG} 2$ monoclonal antibody against CTLA-4 produced by Pfizer, New York, NY), and rarely in those treated with other immune checkpoint inhibitors, such as antibodies against PD-1, ${ }^{12}$ or PDL1. ${ }^{13}$ Overall, however, hypophysitis is the most common endocrine adverse event associated with immune checkpoint inhibitors. ${ }^{14,15}$ In addition, hypophysitis is the most costly adverse event in hospitalized patients with metastatic melanoma, adding an average expense per hospitalization of
$€ 10,265$ in Spain, $€ 5316$ in France, $\$ 9735$ in Canada, $\$ 7231$ in Australia, ${ }^{16}$ and $\$ 8490$ in the United States. ${ }^{17}$ Since the original report, ${ }^{7} 127$ patients have been described in publications as individual case reports or case series (Table 1). A similar number of patients have appeared as counts, without specific information about their clinical characteristics, in studies of ipilimumab or tremelimumab, as recently reviewed by Bertrand et $\mathrm{al}^{15}$ in a meta-analysis of 22 clinical trials.

The pathogenesis of hypophysitis secondary to CTLA-4 blockade remains undetermined, a knowledge gap that often 
leads to increased morbidity and therapy interruptions. Part of the gap relates to the absence of pathologic information, because none of the published patients underwent pituitary biopsy or autopsy. In this study, we report the first pathologically proven cases of hypophysitis secondary to CTLA4 and provide mechanistic insights into the pathogenesis of this emerging condition.

\section{Materials and Methods}

\section{Pathologic Specimens from Autopsy or Surgical Pathology}

\section{Autopsy of Melanoma Cases Treated with CTLA-4 Blockade}

The index case, designated herein as autopsy case 1, was provided by the Saints Anthony and Biagio, and Cesare Arrigo Hospital (Alessandria, Italy), in a 79-year-old woman with a history of environmental asbestos exposure. The patient was diagnosed with unresectable pleural mesothelioma in October 2013 and treated with conventional chemotherapy but without significant response. In October 2014, she began treatment with the CTLA-4 blocking antibody tremelimumab $(10 \mathrm{mg} / \mathrm{kg}$ every 4 weeks $)$. After the third i.v. injection (early December 2014), she developed severe diarrhea, profound fatigue, and vomiting. No signs or symptoms of pituitary mass expansion (headache and/or visual disturbance) or diabetes insipidus (polyuria and polydipsia) were present. Laboratory test results revealed severe hyponatremia $(112 \mathrm{mEq} / \mathrm{L}$; reference range, 135 to $150 \mathrm{mEq} / \mathrm{L})$, mild neutrophilic leukocytosis $(11,300$ cells per microliter with $83 \%$ neutrophils), central adrenal insufficiency [low morning cortisol: $3.1 \mu \mathrm{g} / \mathrm{dL}$ (reference range, 5 to $25 \mu \mathrm{g} / \mathrm{dL}$ ); and inappropriately normal adrenocorticotropic hormone: $12.9 \mathrm{pg} / \mathrm{mL}$ (reference range, 5 to 46 $\mathrm{pg} / \mathrm{mL}$ )], and central hypothyroidism [low free triiodothyronine: $1.38 \mathrm{pg} / \mathrm{mL}$ (reference range, 2.3 to $4.2 \mathrm{pg} / \mathrm{mL}$ ) and low thyroid-stimulating hormone: $0.023 \mathrm{mU} / \mathrm{L}$ (reference range, 0.55 to $4.78 \mathrm{mU} / \mathrm{L}$ )]. Cranial magnetic resonance imaging showed a slightly enlarged pituitary gland (Supplemental Figure S1A), with a height of $6.08 \mathrm{~mm}$ (reference range for sex and age is $4.87 \pm 0.95 \mathrm{~mm}^{18}$ ). On T1-weighted images after contrast, the anterior pituitary contained scattered areas of hypointensity consistent with necrosis (Supplemental Figure S1B). Diagnoses of hypophysitis and colitis were made on clinical and imaging grounds. The patient began glucocorticoids (hydrocortisone, $100 \mathrm{mg}$ four times per day; and methylprednisolone, 250 $\mathrm{mg} / \mathrm{day}$ ), thyroid hormones (levothyroxine, $75 \mu \mathrm{g} / \mathrm{day}$ ), and saline infusions in mid-December. After an initial improvement, she died in January 2015 because of acute respiratory failure. An autopsy was performed.

We then queried the autopsy database of The Johns Hopkins Hospital Pathology Department (searchable electronically from June 1985 to present by authorized personnel) for additional cases and found, as of June 30, 2016, five metastatic melanoma patients who had received ipilimumab, all at a dose of $3 \mathrm{mg} / \mathrm{kg}$ and all without clinical signs and symptoms of hypophysitis.

Autopsy case 2: A 67-year-old man underwent amputation of the third and fourth left toes and sentinel lymph node biopsy in February 2014 for a diagnosis of B-rapidly accelerated fibrosarcoma (BRAF) wild-type melanoma, followed by inguinal, femoral, and pelvic lymph node dissection. Twenty months later, chest and abdominal computed tomographic scans showed enlarged lymph nodes and pulmonary nodules suggestive of metastatic disease, as well as peritoneal carcinomatosis. He began treatment with the anti-CTLA-4 antibody ipilimumab and the anti-PD-1 antibody nivolumab in October 2015. During follow-up, laboratory studies revealed primary hypothyroidism [decreased free thyroxine: $0.7 \mathrm{ng} / \mathrm{dL}$ (reference range, 0.8 to $1.8 \mathrm{ng} / \mathrm{dL}$ ); and increased thyroid-stimulating hormone: $16.8 \mathrm{UI} / \mathrm{L}$ (reference range, 0.5 to $4.5 \mathrm{UI} / \mathrm{L}$ )], severe anemia, and coagulopathy. He received treatment with levothyroxine, anticoagulant, and palliative care but died 2 months later because of widely metastatic disease.

Autopsy case 3: A 30-year-old man underwent resection of a left heel tumor in February 2014 that yielded a diagnosis of lentiginous, BRAF-V600 mutant melanoma. Chest and abdominal computed tomographic scans showed multiple pulmonary nodules, accompanied by mediastinal and hilar lymphadenopathy. Lymph node dissection of the left groin revealed metastatic melanoma. The patient began treatment with the BRAF inhibitor dabrafenib. Repeat imaging in September 2014 showed regression of the lung nodules and pelvic lymph nodes, but appearance of renal and subcutaneous metastases. He then began treatment with ipilimumab, which was discontinued after the first dose because of the appearance of autoimmune hepatitis. In November 2014, the patient received the anti-PD1 monoclonal antibody pembrolizumab but developed colitis, requiring the administration of glucocorticoids. He then developed brain metastases and died in March 2015 because of widely metastatic disease.

Autopsy case 4: A 59-year-old man underwent excision of an ulcerating lesion on the left jaw in June 2010. Pathology showed BRAF wild type and cKit L567P mutant melanoma. The patient began therapy with recombinant IL-2 and remained stable until January 2013 when new pulmonary and adrenal nodules were found. He then received one full treatment cycle with ipilimumab (four doses at 3-week intervals) with minimal response. Pembrolizumab was then administered in the winter of 2013, but new metastases to the rib and omentum were found in July 2014. The patient then underwent treatment with recombinant IL-15 but gradually deteriorated because of the appearance of new metastases. He began a new cycle of ipilimumab in December 2014 but died the following month because of aggressive disease.

Autopsy case 5: A 65-year-old man underwent excision of a mass on his left arm that was shown to be BRAF wild-type melanoma in December 2009. Two years later, the lesion recurred and metastasized to the left axillary lymph nodes. 
The patient received one full cycle of ipilimumab (from September to November 2011) with stabilization of disease. The following year, the arm lesion recurred and ipilimumab was re-established. In February 2013, a chest computed tomographic scan revealed bilateral pleural effusion and soft tissue involvement. He received the anti-PD-1 antibody nivolumab, initially with partial control of the metastases. The patient then developed renal and heart failure, and died in November 2013 after an acute myocardial infarction.

Autopsy case 6: A 58-year-old man underwent resection of a right flank lesion and dissection of right axilla lymph nodes in January 2013, yielding a diagnosis of metastatic melanoma. In February 2014, because of the presence of multiple pulmonary metastases, he began treatment with ipilimumab and nivolumab, obtaining a partial response that eventually prompted the resection of two residual lung metastases in October 2015. Two months later, however, he developed multiple brain metastases and discontinued the immune checkpoint inhibitors. Despite additional treatments, the disease progressed and caused the patient's demise on May 12, 2016.

\section{Surgical Pathology Pituitary Adenomas}

To validate the CTLA-4 immunostainings performed on the six autopsy cases described above, we queried the surgical pathology paraffin block database of The Johns Hopkins Department of Pathology (searchable electronically from March 1984 to present) for pituitary adenomas. Of the total 3274 pituitary surgeries performed in this 33-year interval, 2186 were for pituitary adenomas. We randomly selected 37 specimens, composed of 13 prolactin-secreting, 9 corticotropin-secreting, 8 growth hormone-secreting, and 7 nonsecreting adenomas.

\section{Normal Pituitary Controls}

We also included 11 normal pituitary specimens from autopsy $(n=7)$ or surgical pathology $(n=4)$ sources. All pituitary specimens were deidentified and analyzed blindly (P.C.) under institutional review board protocol number 04-07-12-05e.

\section{Histologic Stainings}

Hematoxylin and Eosin and Masson's Trichrome Stains Pituitary sections were first stained with hematoxylin and eosin and Masson's trichrome to assess morphology and presence of fibrosis.

Immunohistochemistry for Pituitary Hormones and Immunologic Markers

Pituitary sections were then used in immunohistochemistry to detect markers for anterior pituitary hormones, immune cells, immunoglobulins, complement, and CTLA-4.

\section{Anterior pituitary hormones}

Antibodies to the six anterior pituitary hormones (growth hormone, prolactin, adrenocorticotropic hormone, thyroid- stimulating hormone, luteinizing hormone, and folliclestimulating hormone) were used to characterize the type and frequency of adenohypophyseal cells. Immunostainings were performed on the BenchMark Ultra automated stainer (Ventana Medical System, Tucson, AZ) using routine clinical diagnostic protocols.

\section{Immune cells}

Antibodies to CD3 (all T cells), CD4 (helper T cells), CD8 (cytotoxic T cells), CD20 (all B cells), Foxp3 (regulatory $\mathrm{T}$ cells), CD138 (plasma cells), and CD68 (macrophages) were used to characterize the immune infiltrate, using automated stainer and routine protocols.

\section{IgG2, IgG1, and complement C4d}

To determine whether the injected CTLA-4 blocking antibodies had bound in vivo to the patient's own pituitary gland, we stained the pituitary gland with an antibody against human IgG2 (05-3500; Invitrogen, Carlsbad, CA) or human IgG1 (5218-9850; Serotec, Raleigh, NC). We also stained pituitary sections for C4d (BR-RC4d; ALPCO, Salem, NH), a complement component that binds covalently to surfaces where complement activation is initiated. These experiments were performed manually, with 10-minute antigen retrieval and 30-minute incubations.

\section{CTLA-4}

A mouse monoclonal antibody directed against human CTLA-4 (clone 14D3; eBioscience, San Diego, CA) was optimized on the spleen to achieve an optimal signal/noise ratio, which corresponded to a concentration of $2.5 \mu \mathrm{g} / \mathrm{mL}$. The protocol was then added to the automated stainer and used to analyze our collection of autopsy pituitary sections.

\section{Double indirect immunofluorescence}

We used the pituitary gland from autopsy case 6 (which, as discussed in Results, showed pathologic evidence of mild hypophysitis and retained great part of the normal pituitary architecture) to extend our original report of CTLA-4 expression in a subset of prolactin- and thyrotropin-secreting cells. ${ }^{19}$ A portion of this gland was frozen in optimal cutting temperature compound, cut (5 $\mu \mathrm{m}$ thick), and double stained for CTLA-4 plus one of the antibodies directed against prolactin, thyroid-stimulating hormone, follicle-stimulating hormone, luteinizing hormone, adrenocorticotropic hormone, or growth hormone (information regarding these antibodies can be found in the study by Iwama et $\mathrm{al}^{19}$ ). Sections were stained as described by Pollock et al. ${ }^{20}$ Then, cells were counted at $40 \times$ to calculate the total number of endocrine cells and, of them, the number of cells positive for the hormone, CTLA-4, or both.

\section{Statistical Analysis}

Pituitary CTLA-4 expression was scored on a continuous scale from 0 (no cell stained) to 300 (all cells stained strongly), using the semiquantitative system we previously 
published. ${ }^{21}$ The score was modeled by multiple linear regression using three predictors: diagnostic category (coded as 0 for normal pituitary and 1 for autopsy pituitaries of patients treated with CTLA-4 blocking antibodies), sex, and age. Differences in the proportions of patients with a particular clinical feature when comparing primary to secondary hypophysitis were assessed by Fisher's exact test. Statistical analyses were performed using Stata software release 14 (Stata, College Station, TX).

\section{Results}

\section{CTLA-4 Blockade Can Induce a Necrotizing Form of Hypophysitis}

The most striking pathologic feature of autopsy case 1 was the near complete destruction of her anterior pituitary gland, because of extensive necrosis (in approximately $30 \%$ of the parenchyma) (Figure 1A) and fibrosis (Figure 1B). Only a few acini of endocrine cells remained in two isolated areas of the gland (Figure 1A), which were heavily infiltrated with hematopoietic mononuclear cells (Figure 1, C and D). The few remaining endocrine cells were mainly of the acidophil class (Figure 1E) and growth hormone producing (Figure 1F). Prolactin- or adrenocorticotropic hormone-producing cells were rare, and gonadotrophs and thyrotrophs absent (data not shown). The posterior pituitary was normal (data not shown), consistent with the absence of central diabetes insipidus in our patients, and the rarity of diabetes insipidus in the published cases [1 (0.9\%) of 116] (Table 1).

The histologic appearance of the other autopsy cases, who also had received CTLA-4 blockade for the treatment of their melanoma but had not developed clinical or radiological signs of hypophysitis, was that of a normal pituitary gland for cases 2 through 5 (data not shown), and that of mild lymphocytic hypophysitis for case 6 (as presented below).

\section{Evidence of Type IV Hypersensitivity Mechanisms}

Type IV hypersensitivity reactions, commonly seen in autoimmune diseases, are mediated by $\mathrm{T}$ lymphocytes that cause tissue damage by production of cytokines, activation of B lymphocytes and phagocytes, and direct granzyme/ perforin-mediated cytotoxicity. ${ }^{22}$ The pituitary gland of
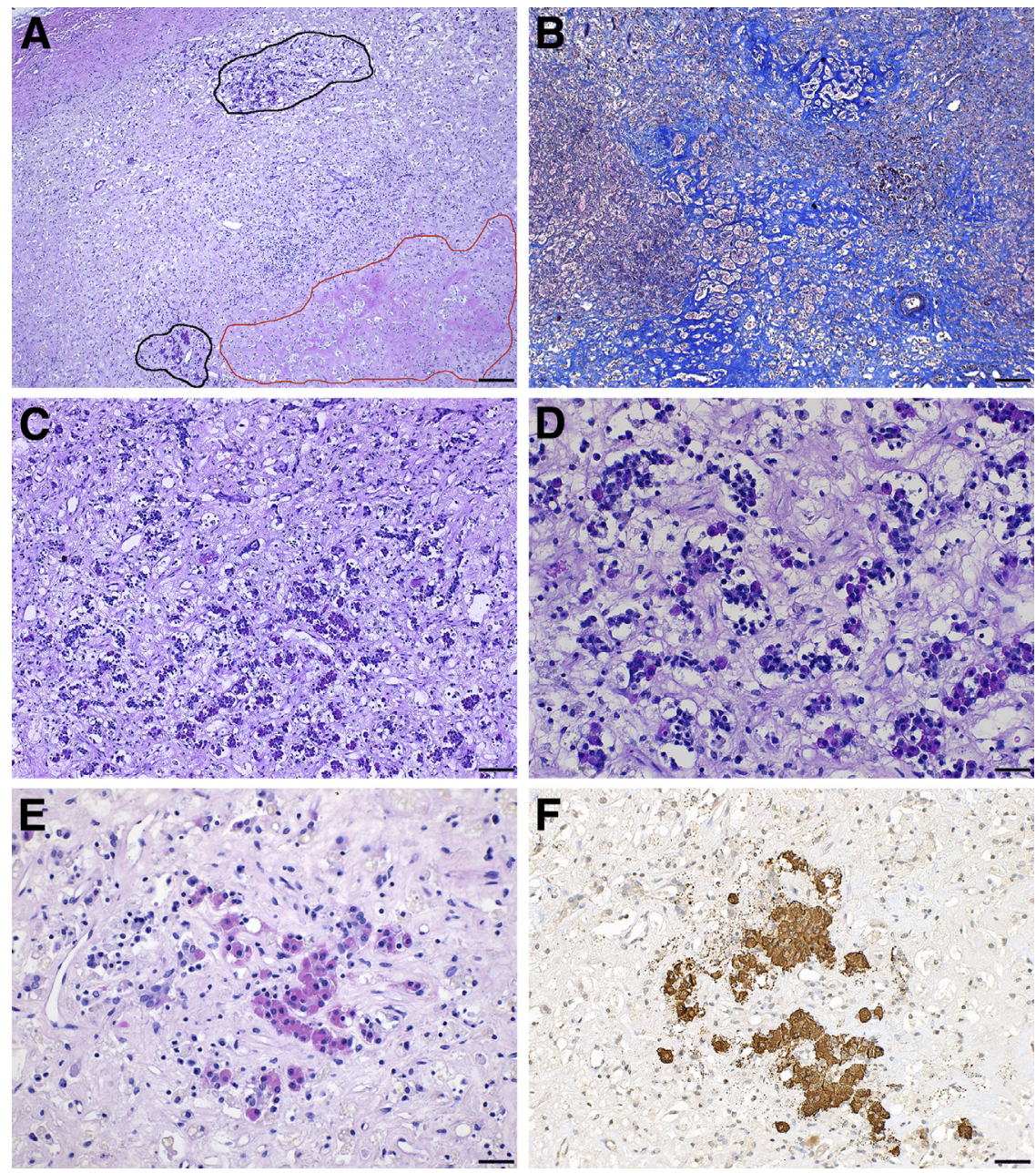

Figure 1 Necrotizing hypophysitis induced by administration of a CTLA-4 blocking antibody. A: Hematoxylin and eosin (H\&E) low power view of the anterior pituitary of the autopsy index case, to show a large necrotic area (red outline), the mononuclear cell infiltration (in the center of the field), and the rarity of endocrine acini remaining (black outline). B: Masson's trichrome staining to show (turquoise) the extensive fibrosis. C and D: H\&E mid (C) and high (D) power view of one of the remaining areas containing pituitary endocrine cells, showing the marked infiltration with hematopoietic mononuclear cells (E) H\&E mid power to show an island of remaining acidophils, that stain positive for growth hormone (F). Scale bars: $200 \mu \mathrm{m}$ (A and B); $100 \mu \mathrm{m}$ (C); $50 \mu \mathrm{m}$ (D-F). Original magnification: $\times 20(\mathbf{A}$ and $\mathbf{B}) ; \times 40$ (C); $\times 100$ (D); $\times 64$ (E and F). 

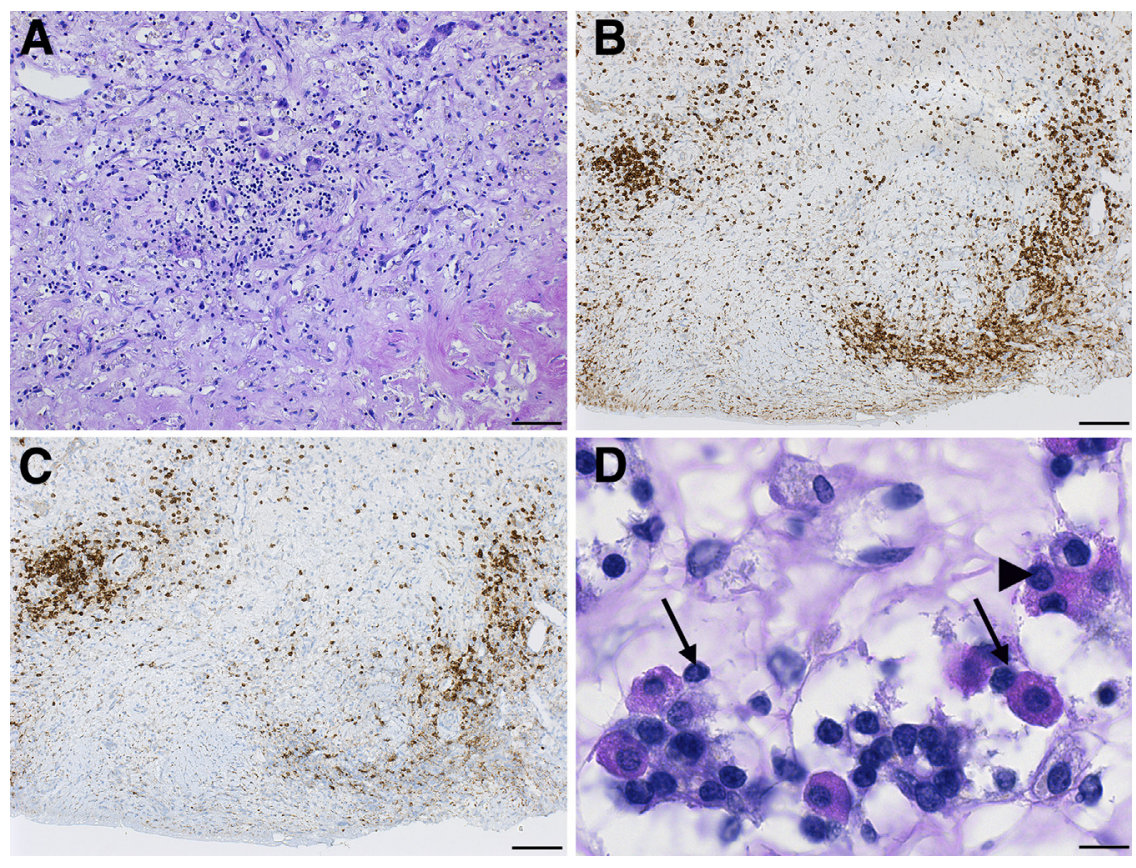

Figure 2 Evidence of type IV hypersensitivity mechanisms in the pituitary gland of the autopsy case. A: Diffuse infiltration of the anterior pituitary with lymphocytes. Lymphocytes are CD4-positive T cells (B) and CD20-positive B cells (C). D: Lymphocytes intimately contact the pituitary acidophil cells (arrows), and in some cases penetrate in their cytosol (arrowhead). Scale bars: $50 \mu \mathrm{m}$ (A); $100 \mu \mathrm{m}$ (B and C); $20 \mu \mathrm{m}$ (D). Original magnification: $\times 64($ A $) ; \times 40(B$ and C); $\times 260$ (D).

autopsy case 1 was markedly infiltrated with lymphocytes, scattered throughout the parenchyma (Figure 2A) or occasionally aggregating to form ectopic lymphoid follicles, a hallmark of autoimmune pathology. Lymphocytes were mainly composed of CD4-positive T cells (Figure 2B) and CD20-positive B cells (Figure 2C). They made intimate contact with the endocrine cells (Figure 2D) and in some cases penetrated their cytosol (Figure 2D), a phenomenon known as emperipolesis, also a feature of autoimmune pathology.

The autopsy of case 6 , who had no clinical or radiological signs of hypophysitis, showed pathologic evidence of mild lymphocytic hypophysitis. This consisted of a fine, extravascular presence of lymphocytes scattered throughout the pituitary parenchyma, at times clustered in groups of three to five cells (Supplemental Figure S2A) and associated with loss of the normal endocrine cells (Supplemental Figure S2A). The infiltrating cells were mainly CD3positive T cells (Supplemental Figure S2B).

\section{Evidence of Type II Hypersensitivity Mechanisms}

Type II hypersensitivity reactions are mediated by $\operatorname{IgG}$ antibodies that bind to antigens expressed on target cells. ${ }^{22}$ This binding causes tissue damage by promoting phagocytosis of the target via macrophages and activating the complement cascade. The pituitary gland of the index case was heavily infiltrated with CD68-positive macrophages, which represented the most abundant hematopoietic cell type (Figure 3A). Macrophages permeated throughout the entire parenchyma and featured a prominent, vacuolated, foamy cytoplasm (Figure 3A). They contained fragments of endocrine cells inside their cytoplasm. For example, remnants of prolactin-secreting cells were observed inside the phagocytic macrophages (Figure 3B). Macrophages did not fuse to form multinucleated giant cells or assume the epithelioid appearance typically seen in granulomas.

Staining with an anti-IgG2 antibody revealed in autopsy case 1 the presence of $\mathrm{IgG} 2$ on some of the remaining pituitary cells (Figure 3C), suggesting that the administered tremelimumab (an IgG2 antibody) had bound to its target (CTLA-4) on the pituitary cells. No significant pituitary cell staining was found for IgG1 (Figure 3C) or IgG2 in the other autopsy pituitary glands. The complement factor $\mathrm{C} 4 \mathrm{~d}$ was found to be deposited onto the pituitary cells (Figure 3D) and vessels (Figure 3D) of the index case. No $\mathrm{C} 4 \mathrm{~d}$ staining was seen in the other pituitary glands (Figure 3D).

\section{Expression of CTLA-4 by Pituitary Endocrine Cells}

In autopsy case 1, CTLA-4 protein assessed by immunohistochemistry was expressed strongly in the few remaining pituitary endocrine cells (Figure 4A). The expression was cytosolic and granular in appearance (Figure 4A). Fragments of CTLA-4-positive endocrine cells were also found inside the infiltrating macrophages (Figure 4A), indicating that they had phagocytized pituitary cells expressing CTLA-4.

In the other five melanoma cases treated with ipilimumab, as well as in the 37 pituitary adenomas and 11 normal pituitary controls, the expression of CTLA-4 varied greatly and did not differ among the three groups (Figure 4B), even after adjusting for sex, age, and 


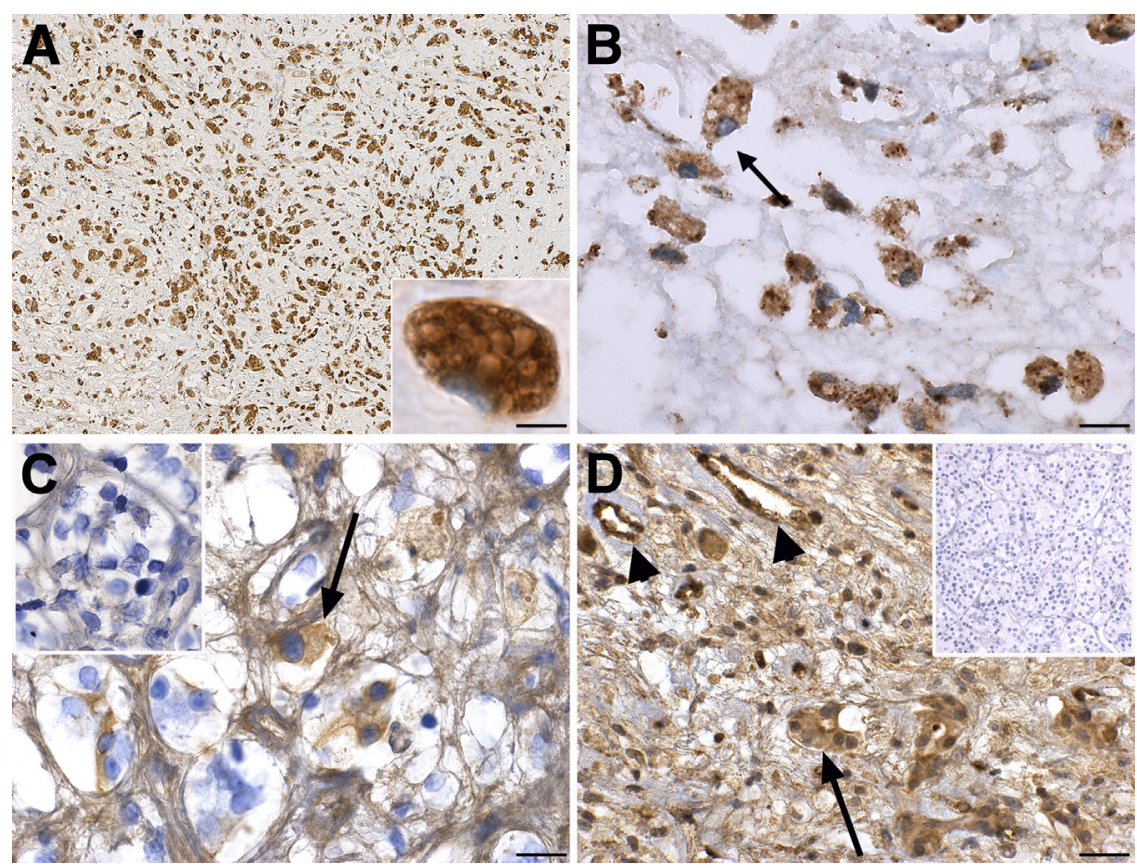

Figure 3 Evidence of type II hypersensitivity mechanisms in the pituitary gland of the autopsy case. A: CD68 staining showing the marked infiltration of the gland with macrophages. The inset shows at high power a single macrophage with prominent vacuolated cytoplasm. B: High power view of prolactin staining to show that the positivity is found almost exclusively inside the cytosol of macrophages. C: Binding of IgG2 immunoglobulins to pituitary endocrine cells (arrow) of the case. The inset shows at the same magnification the absence of staining for IgG1. D: Deposition of complement $\mathrm{C} 4 \mathrm{~d}$ on some pituitary endocrine cells (arrow) and endothelial cells (arrowheads) of the case. The inset shows the absence of Cd4 deposition in a control pituitary. Scale bars: $100 \mu \mathrm{m}$ (A); $20 \mu \mathrm{m}$ (B and C); $50 \mu \mathrm{m}$ (D). Original magnification: $\times 40$ (A, main image); $\times 260($ A, inset, $B$, and C, main image and inset); $\times 160$ (D, main image and inset).

adenoma type (data not shown). In some patients, CTLA-4 was expressed strongly by most pituitary endocrine cells (Figure 4C). In others, it was expressed at moderate levels by a subset of pituitary cells (Figure 4D). In others yet, CTLA-4 was not expressed, giving the appearance shown in Figure 4D. In contrast to what is known for regulatory $\mathrm{T}$ cells, the expression of CTLA-4 in pituitary endocrine cells seemed independent of Foxp3. This transcription factor, in fact, was not expressed in autopsy case 1 (Supplemental Figure S3A) and the other pituitary cases (Supplemental Figure S3B).

Staining the pituitary gland of autopsy case 6 , which had minimal lymphocytic infiltration and thus conserved the normal acinar architecture, using antibodies to CTLA-4 and one of the six adenohypophyseal hormones, revealed that CTLA-4-positive cells, as assessed by double immunofluorescence, represented approximately $1.5 \%$ of the total endocrine cells (Table 2) and included
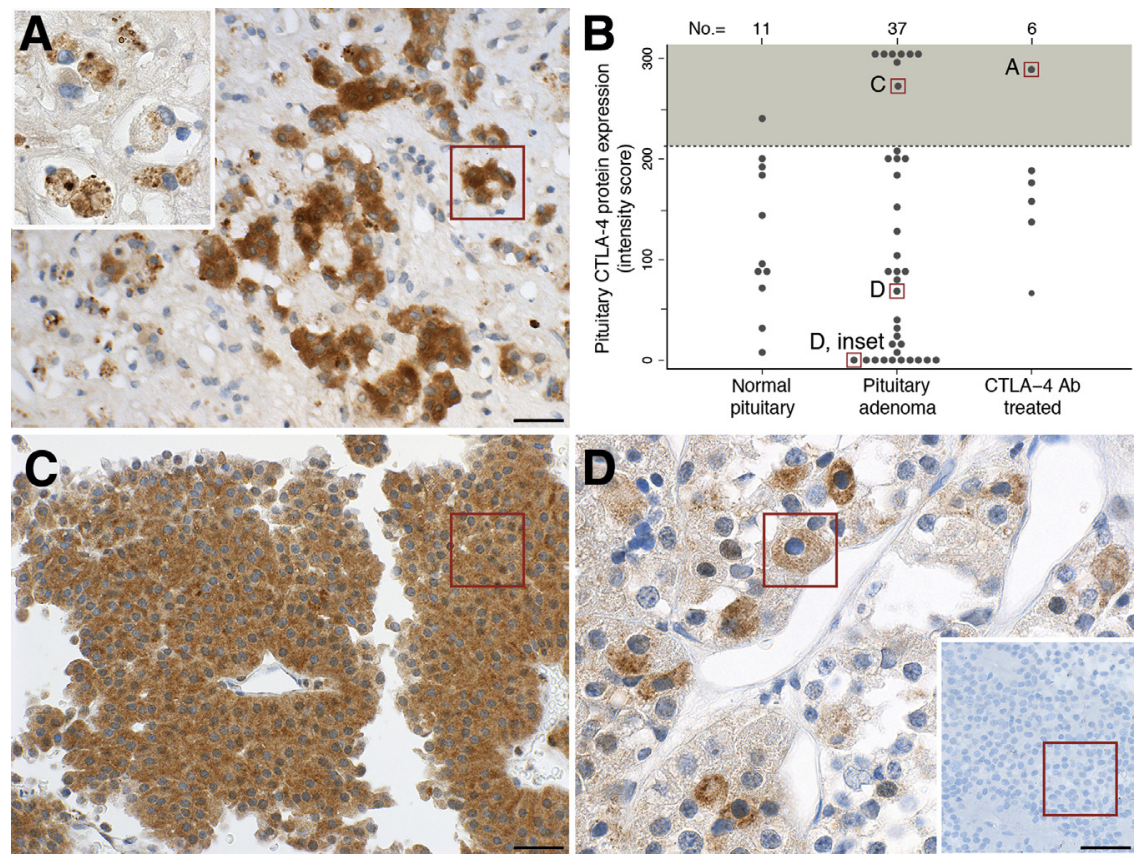

Figure 4 Expression of pituitary CTLA- 4 in the human pituitary gland at autopsy. A: In the index case, the few remaining acini of endocrine cells in the pituitary strongly express CTLA-4. The inset shows that CTLA-4-positive granules are found inside the cytosol of infiltrating macrophages. B: Histopathologic score to quantify the expression of pituitary CTLA- 4 protein in the study population; lettered boxes correlate to the boxed areas in the indicated panels. The shaded area above the dotted lines indicates the specimens that express CTLA- 4 at high intensity in most endocrine pituitary cells. C: A pituitary adenoma expressing CTLA-4 strongly. D: A pituitary adenoma expressing CTLA-4 at moderate levels in a subset of endocrine cells; the inset shows a pituitary adenoma negative for CTLA-4. Scale bars: $50 \mu \mathrm{m}$ (A and C); $20 \mu \mathrm{m}$ (D). Original magnifications: $\times 100$ (A, main image); $\times 260$ (A, inset, and $D$, main image); $\times 160$ (C and D, inset). 
Table 2 Distribution of Hormone-Secreting and CTLA-4-Expressing Pituitary Cells by Double Indirect Immunofluorescence in the Gland from Autopsy Case 6

\begin{tabular}{lllll}
\hline Antibody stainings & Total endocrine cells & Hormone-positive cells* & CTLA-4-positive cells* & Double-positive cells \\
\hline GH and CTLA-4 & 116 & $64(55)$ & $1(0.9)$ & 0 \\
PRL and CTLA-4 & 110 & $22(20)$ & $2(1.8)$ & 0 \\
ACTH and CTLA-4 & 92 & $13(14)$ & $1(1.1)$ & 0 \\
FSH and CTLA-4 & 114 & $12(10)$ & $3(2.6)$ & 2 \\
LH and CTLA-4 & 106 & $6(6)$ & $2(1.9)$ & 2 \\
TSH and CTLA-4 & 128 & $5(4)$ & $1(0.8)$ & 1 \\
\hline
\end{tabular}

Numbers indicate the average number of cells in three $\times 40$ microscopic fields. The term endocrine pituitary cells indicates the total number of DAPI-positive cells found inside the acini.

*Data are given as $n(\%)$.

ACTH, adrenocorticotropic hormone; CTLA-4, cytotoxic T-lymphocyte-associated protein 4; FSH, follicle-stimulating hormone; GH, growth hormone; LH, luteinizing hormone; PRL, prolactin; TSH, thyroid-stimulating hormone.

gonadotropin-secreting (Figure 5) and thyrotropinsecreting (data not shown) cells.

\section{Discussion}

Hypophysitis secondary to administration of CTLA-4 blocking antibodies is expected to increase in prevalence as the use of cancer immunotherapies grows and diversifies. $^{23}$ Several review articles have been published on this topic in recent months. ${ }^{14,15,24,25}$ Secondary hypophysitis has features that markedly differ from those of primary hypophysitis, which we have summarized in Table 1. It predilects males [100 (79\%) of 127 published patients versus 287 (29\%) of 1005 in primary hypophysitis; $P<0.001]$ and older ages $(59 \pm 13$ years versus $41 \pm 16$ years; $P<0.001$ ), in part reflecting the demographics of the underlying cancer. It presents insidiously with vague symptoms referable to cortisol deficiency, which often overlap with those related to cancer. ${ }^{26}$ Headache is more common than in primary hypophysitis, but not as severe. Visual disturbances and diabetes insipidus, on the contrary, are extremely rare. At diagnosis, endocrine deficits are pronounced and involve the adrenal, thyroid, and gonadal axes with similar frequencies. Cranial magnetic resonance imaging, almost always abnormal in the primary forms, is normal in approximately a fifth of the cancer patients who develop hypophysitis after CTLA-4 blockade. Overall, hypophysitis secondary to CTLA-4 blockade is difficult to diagnose unless there is a high index of suspicion. Most patients acquire permanent hypopituitarism ${ }^{27}$ and cannot discontinue the glucocorticoid replacement because of persistent secondary adrenal insufficiency. ${ }^{28}$ Furthermore, glucocorticoids, of proven efficacy in primary hypophysitis, might not be beneficial. ${ }^{11}$

The mechanisms underlying the pathogenesis of CTLA4-related hypophysitis have remained undefined. The present autopsy series suggests that the disease results from a combination of inflammatory and autoimmune mechanisms, schematically summarized in Figure 6. The early events are likely to be inflammatory type II hypersensitivity reactions: the CTLA-4 antibody administered therapeutically binds to pituitary CTLA-4 antigen, inducing the formation of immune complexes that recruit complement $\mathrm{Clq}$ molecules and activate the classic pathway, leading to the formation of products such as $\mathrm{C} 3, \mathrm{C} 3 \mathrm{~d}$, and $\mathrm{C} 4 \mathrm{~d}$. These products damage
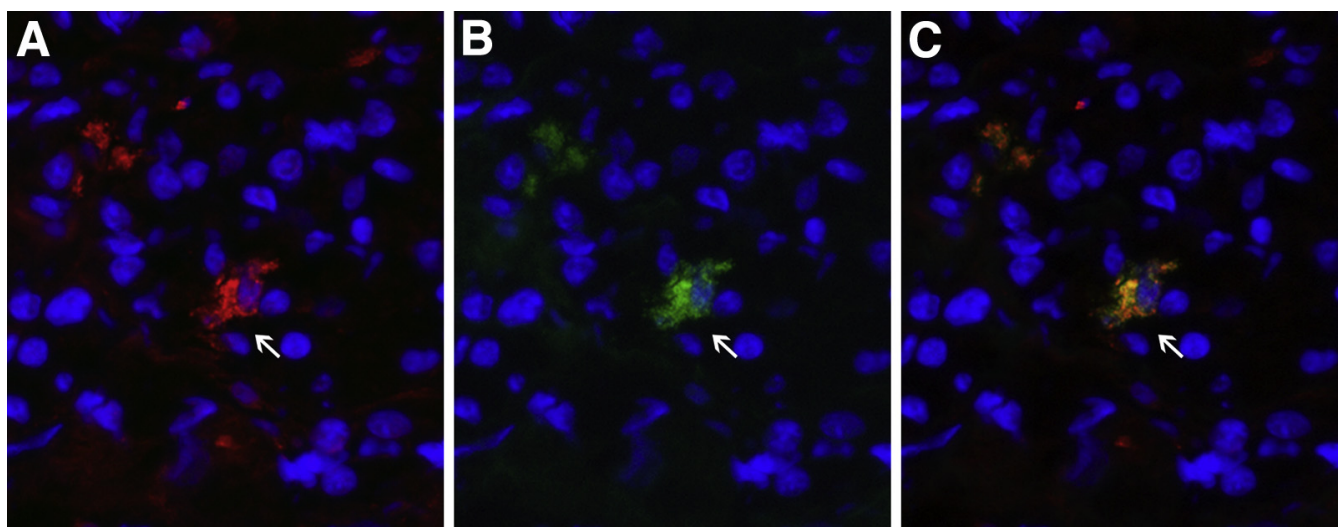

Figure 5 Double indirect immunofluorescence using the pituitary of autopsy case 6 as substrate and antibodies to follicle-stimulating hormone (FSH)- $\beta$ and CTLA-4. A: Staining with anti-FSH- $\beta$ identifies a clear positive cell (arrows). B: The same cell is also stained with anti-CTLA-4. C: Merging of the red $($ FSH- $\beta)$ and green (CTLA-4) channel yields a yellowish cell indicating colocalization. Original magnificaiton, $\times 40(\mathbf{A}-\mathbf{C})$. 


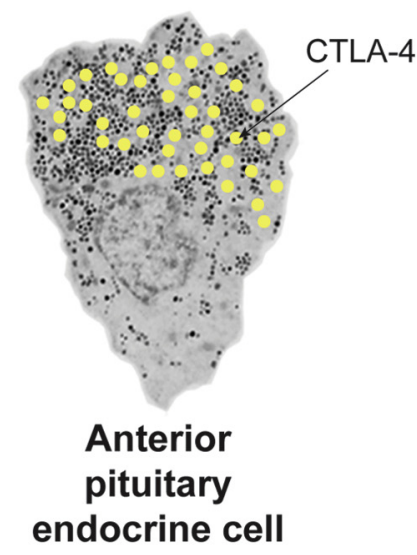

Expression: on a subset of adenohypophyseal endocrine cells, at different levels in different individuals

Function: unknown

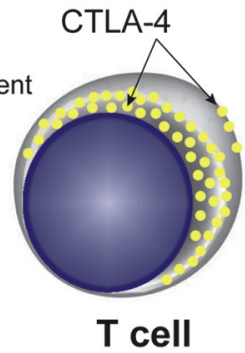

Expression: on regulatory T cells constitutively, and effector

$T$ cells upon activation

Function: CTLA-4 limits excessive activation and expansion of effector T cells

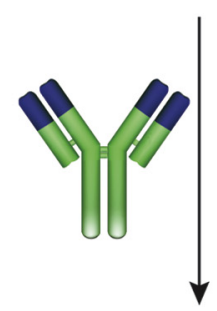

T cell

Therapeutic administration of a monoclonal antibody blocking CTLA-4
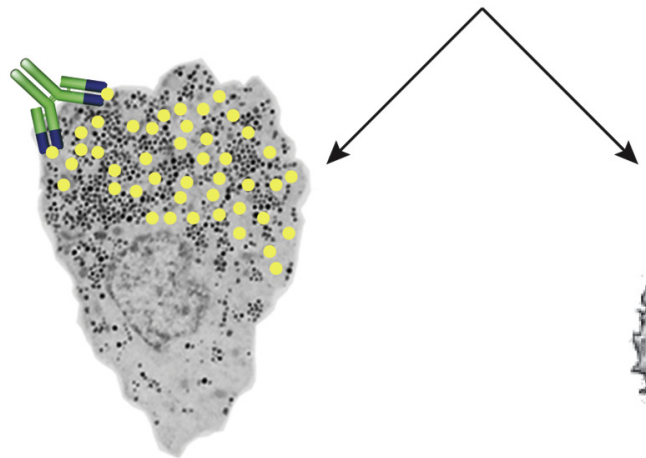

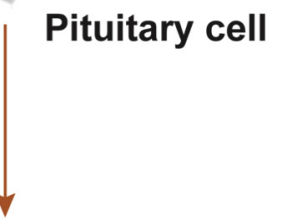

Type II hypersensitivity: complement activation infiltration with macrophages and phagocytosis

Type IV hypersensitivity: infiltration with autoreactive T lymphocytes

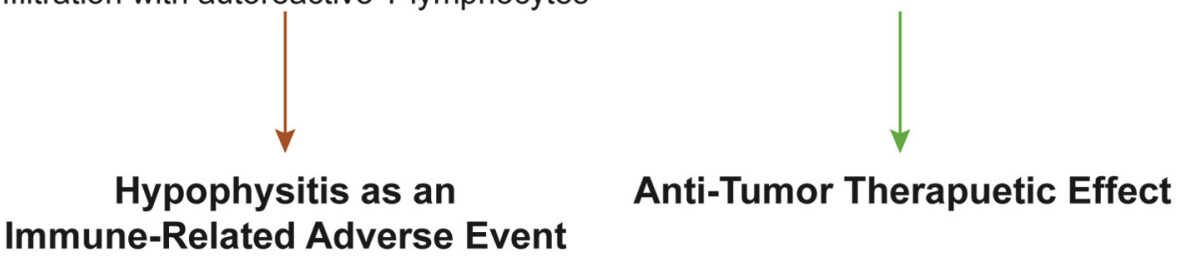

Figure 6 Schematic representation of the mechanism of action of CTLA-4 blocking antibodies. Administration of a CTLA-4 blocking antibody binds to CTLA-4 expressed on T lymphocytes, leading to the beneficial expansion of effector T cells that recognize novel tumor antigens and eliminate the tumor (right side). The same administered antibody, however, also binds to CTLA-4 expressed on pituitary cells, leading to type II and type IV hypersensitivity mechanisms that cause hypophysitis and pituitary cytotoxicity (left side).

the pituitary cells and recruit macrophages and other inflammatory cells, leading to phagocytosis and enhanced antigen presentation. Later events comprise autoimmune type IV hypersensitivity reactions, characterized by infiltration with lymphocytes that organize into ectopic lymphoid follicles and intimately contact the pituitary endocrine cells.

It is informative to speculate on the cellular location of CTLA-4 expression, as it likely relates to the pathogenesis of secondary hypophysitis. In $\mathrm{CD}^{+}{ }^{+} \mathrm{T}$ cells, CTLA-4 is 
found both in the cytosol and on the plasma membrane, depending on the subset of $\mathrm{CD} 4^{+} \mathrm{T}$ cells and their functional state. For example, Tai et $\mathrm{al}^{29}$ have shown by confocal microscopy that in the resting state CTLA-4 is expressed in cytosolic vesicles of the Golgi apparatus in conventional $\mathrm{CD}^{+}{ }^{+} \mathrm{T}$ cells, and in vesicles clustered under the inner side of the plasma membrane in regulatory $\mathrm{CD}_{4}^{+}$ $\mathrm{T}$ cells. On activation through the T-cell receptor, CTLA-4 becomes externalized and found on the outer side of the plasma membrane, as well as released into the extracellular space as soluble CTLA- $4 .^{29}$ The traditional techniques of immunohistochemistry and immunofluorescence used in this study suggest that in pituitary cells CTLA-4 is found in fine cytosolic granules. If these findings are confirmed with more sensitive techniques, it remains to be demonstrated how antibodies directed against CTLA-4 find their intracellular target. This is an extensively discussed topic in autoimmunity that warrants further studies. For example, in patients with Sjögren syndrome and systemic lupus erythematosus, it remains unknown how antibodies to nuclear antigens (such as Ro/SSA, La/SSB, and doublestranded DNA) penetrate the cell, bind to their cognate antigen, and cause pathologic damage. ${ }^{30}$

This study also shows that the expression of pituitary CTLA-4, a T-cell molecule that we reported to be expressed also by pituitary endocrine cells, ${ }^{19}$ varies greatly among individuals. In $\mathrm{T}$ cells, single-nucleotide polymorphisms in the CTLA-4 gene have been associated with different expression levels of CTLA- $4 .{ }^{31}$ For example, a substitution at the J030 polymorphism decreased the expression of lymphoid CTLA-4 and related to better response to CTLA-4 blockade in melanoma patients. ${ }^{32}$ In pituitary endocrine cells, the expression of CTLA-4 remains to be fully characterized, but we can envision that patients who express the highest levels of pituitary CTLA4 are those at greatest risk of developing the aggressive form of necrotizing hypophysitis described in case 1 of this autopsy series. CTLA- 4 genotyping might therefore help to stratify patients undergoing immunotherapy not only for their response to therapy, ${ }^{33}$ but also for their risk of developing hypophysitis.

In summary, we observed type II and IV hypersensitivity reactions and strong CTLA-4 expression in the pituitary gland of a cancer patient who died after CTLA-4 blockade. Our findings are consistent with a disease mechanism wherein administered CTLA-4 antibody binds to pituitary CTLA- 4 and initiates a series of cytopathic immune reactions (complement fixation, phagocytosis, and autoreactive lymphocyte activation) that ultimately lead to pituitary pathology and clinical disease.

\section{Acknowledgments}

We thank Dr. Egle Ansaldi for her teaching and mentorship, Drs. Roberta Libener and Narciso Mariani and Valter
Declame for their assistance with the autopsy (Saints Anthony and Biagio, and Cesare Arrigo Hospital, Alessandria, Italy); and Astra-Zeneca for reviewing the manuscript.

\section{Supplemental Data}

Supplemental material for this article can be found at http://dx.doi.org/10.1016/j.ajpath.2016.08.020.

\section{References}

1. Leporati P, Landek-Salgado MA, Lupi I, Chiovato L, Caturegli P: IgG4-related hypophysitis: a new addition to the hypophysitis spectrum. J Clin Endocrinol Metab 2011, 96:1971-1980

2. Caturegli P, Iwama S: From Japan with love: another tessera in the hypophysitis mosaic. J Clin Endocrinol Metab 2013, 98:1865-1868

3. Caturegli P, Newschaffer C, Olivi A, Pomper MG, Burger PC, Rose NR: Autoimmune hypophysitis. Endocr Rev 2005, 26:599-614

4. Deodhare SS, Bilbao JM, Kovacs K, Horvath E, Nomikos P, Buchfelder M, Reschke K, Lehnert H: Xanthomatous hypophysitis: a novel entity of obscure etiology. Endocr Pathol 1999, 10:237-241

5. van der Vliet HJ, Perenboom RM: Multiple pseudotumors in IgG4associated multifocal systemic fibrosis. Ann Intern Med 2004, 141: 896-897

6. Ahmed SR, Aiello DP, Page R, Hopper K, Towfighi J, Santen RJ Necrotizing infundibulo-hypophysitis: a unique syndrome of diabetes insipidus and hypopituitarism. J Clin Endocrinol Metab 1993, 76: 1499-1504

7. Phan GQ, Yang JC, Sherry RM, Hwu P, Topalian SL, Schwartzentruber DJ, Restifo NP, Haworth LR, Seipp CA, Freezer LJ, Morton KE, Mavroukakis SA, Duray PH, Steinberg SM, Allison JP, Davis TA, Rosenberg SA: Cancer regression and autoimmunity induced by cytotoxic $\mathrm{T}$ lymphocyte-associated antigen 4 blockade in patients with metastatic melanoma. Proc Natl Acad Sci U S A 2003, $100: 8372-8377$

8. Gutenberg A, Landek-Salgado MA, Tzou SC, Lupi I, Geis A, Kimura H, Caturegli P: Autoimmune hypophysitis: expanding the differential diagnosis to CTLA-4 blockade. Expert Rev Endocrinol Metab 2009, 4:681-698

9. Albarel F, Gaudy C, Castinetti F, Carre T, Morange I, Conte-Devolx B, Grob JJ, Brue T: Long-term follow-up of ipilimumab-induced hypophysitis, a common adverse event of the anti-CTLA-4 antibody in melanoma. Eur J Endocrinol 2014, 172:195-204

10. Faje AT, Sullivan R, Lawrence D, Tritos NA, Fadden R, Klibanski A, Nachtigall L: Ipilimumab-induced hypophysitis: a detailed longitudinal analysis in a large cohort of patients with metastatic melanoma. J Clin Endocrinol Metab 2014, 99:4078-4085

11. Min L, Hodi FS, Giobbie-Hurder A, Ott PA, Luke JJ, Donahue H, Davis M, Carroll RS, Kaiser UB: Systemic high dose corticosteroid treatment does not improve the outcome of ipilimumab-related hypophysitis: a retrospective cohort study. Clin Cancer Res 2014, 21: 749-755

12. Topalian SL, Hodi FS, Brahmer JR, Gettinger SN, Smith DC, McDermott DF, Powderly JD, Carvajal RD, Sosman JA, Atkins MB Leming PD, Spigel DR, Antonia SJ, Horn L, Drake CG, Pardoll DM, Chen L, Sharfman WH, Anders RA, Taube JM, McMiller TL, Xu H, Korman AJ, Jure-Kunkel M, Agrawal S, McDonald D, Kollia GD, Gupta A, Wigginton JM, Sznol M: Safety, activity, and immune correlates of anti-PD-1 antibody in cancer. N Engl J Med 2012, 366 : 2443-2454

13. Brahmer JR, Tykodi SS, Chow LQ, Hwu WJ, Topalian SL, Hwu P, Drake CG, Camacho LH, Kauh J, Odunsi K, Pitot HC, Hamid O, Bhatia S, Martins R, Eaton K, Chen S, Salay TM, Alaparthy S, Grosso JF, Korman AJ, Parker SM, Agrawal S, Goldberg SM, 
Pardoll DM, Gupta A, Wigginton JM: Safety and activity of anti-PD-L1 antibody in patients with advanced cancer. N Engl J Med 2012, 366:2455-2465

14. Abdel-Rahman O, ElHalawani H, Fouad M: Risk of endocrine complications in cancer patients treated with immune check point inhibitors: a meta-analysis. Future Oncol 2016, 12:413-425

15. Bertrand A, Kostine M, Barnetche $\mathrm{T}$, Truchetet ME, Schaeverbeke T: Immune related adverse events associated with anti-CTLA-4 antibodies: systematic review and meta-analysis. BMC Med 2015, 13:211

16. Wehler E, Zhao Z, Pinar Bilir S, Munakata J, Barber B: Economic burden of toxicities associated with treating metastatic melanoma in eight countries. Eur J Health Econ 2015, [Epub ahead of print] doi:10.1007/s10198-015-0757-y

17. Barzey V, Atkins MB, Garrison LP, Asukai Y, Kotapati S, Penrod JR: Ipilimumab in 2nd line treatment of patients with advanced melanoma: a cost-effectiveness analysis. J Med Econ 2013, 16:202-212

18. Tsunoda A, Okuda O, Sato K: MR height of the pituitary gland as a function of age and sex: especially physiological hypertrophy in adolescence and in climacterium. AJNR Am J Neuroradiol 1997, 18: $551-554$

19. Iwama S, De Remigis A, Callahan MK, Slovin SF, Wolchok JD, Caturegli P: Pituitary expression of ctla-4 mediates hypophysitis secondary to administration of ctla-4 blocking antibody. Sci Transl Med 2014, 6:230ra45

20. Pollock AJ, Seibert TS, Salvatori C, Caturegli P, Allen DB: Pituitary antibodies in an adolescent with secondary adrenal insufficiency and Turner syndrome. Hormone Res Paediatr 2016, [Epub ahead of print] doi: $10.1159 / 000446912$

21. Zheng G, Chaux A, Sharma R, Netto G, Caturegli P: LMP2, a novel immunohistochemical marker to distinguish renal oncocytoma from the eosinophilic variant of chromophobe renal cell carcinoma. Exp Mol Pathol 2013, 94:29-32

22. Uzzaman A, Cho SH: Classification of hypersensitivity reactions. Allergy Asthma Proc 2012, 33(Suppl 1):S96-S99

23. Faje A: Immunotherapy and hypophysitis: clinical presentation, treatment, and biologic insights. Pituitary 2015, 19:82-92

24. Joshi MN, Whitelaw BC, Palomar MT, Wu Y, Carroll PV: Immune checkpoint inhibitor related hypophysitis and endocrine dysfunction: clinical review. Clin Endocrinol (Oxf) 2016, 85:331-339
25. Michot JM, Bigenwald C, Champiat S, Collins M, Carbonnel F, Postel-Vinay S, Berdelou A, Varga A, Bahleda R, Hollebecque A, Massard C, Fuerea A, Ribrag V, Gazzah A, Armand JP, Amellal N, Angevin E, Noel N, Boutros C, Mateus C, Robert C, Soria JC, Marabelle A, Lambotte O: Immune-related adverse events with immune checkpoint blockade: a comprehensive review. Eur J Cancer 2016, 54:139-148

26. Crowne E, Gleeson H, Benghiat H, Sanghera P, Toogood A: Effect of cancer treatment on hypothalamic-pituitary function. Lancet Diabetes Endocrinol 2015, 3:568-576

27. Tiu C, Pezaro C, Davis ID, Grossmann M, Parente P: Early recognition of ipilimumab-related autoimmune hypophysitis in patients with metastatic melanoma: case studies and recommendations for management. Asia Pac J Clin Oncol 2015, 11:190-194

28. Mahzari M, Liu D, Arnaout A, Lochnan H: Immune checkpoint inhibitor therapy associated hypophysitis. Clin Med Insights Endocrinol Diabetes 2015, 8:21-28

29. Tai X, Van Laethem F, Pobezinsky L, Guinter T, Sharrow SO, Adams A, Granger L, Kruhlak M, Lindsten T, Thompson CB, Feigenbaum L, Singer A: Basis of CTLA-4 function in regulatory and conventional CD4(+) T cells. Blood 2012, 119:5155-5163

30. Szczerba BM, Kaplonek P, Wolska N, Podsiadlowska A, Rybakowska PD, Dey P, Rasmussen A, Grundahl K, Hefner KS, Stone DU, Young S, Lewis DM, Radfar L, Scofield RH, Sivils KL, Bagavant H, Deshmukh US: Interaction between innate immunity and Ro52-induced antibody causes Sjogren's syndrome-like disorder in mice. Ann Rheum Dis 2016, 75:617-622

31. Gough SC, Walker LS, Sansom DM: CTLA4 gene polymorphism and autoimmunity. Immunol Rev 2005, 204:102-115

32. Sanderson K, Scotland R, Lee P, Liu D, Groshen S, Snively J, Sian S, Nichol G, Davis T, Keler T, Yellin M, Weber J: Autoimmunity in a phase I trial of a fully human anti-cytotoxic T-lymphocyte antigen-4 monoclonal antibody with multiple melanoma peptides and Montanide ISA 51 for patients with resected stages III and IV melanoma. J Clin Oncol 2005, 23:741-750

33. Breunis WB, Tarazona-Santos E, Chen R, Kiley M, Rosenberg SA, Chanock SJ: Influence of cytotoxic T lymphocyte-associated antigen 4 (CTLA4) common polymorphisms on outcome in treatment of melanoma patients with CTLA-4 blockade. J Immunother 2008, 31: 586-590 